\title{
Alzheimer's Proteins, Oxidative Stress, and Mitochondrial Dysfunction Interplay in a Neuronal Model of Alzheimer's Disease
}

\author{
Antonella Bobba, Vito A. Petragallo, Ersilia Marra, and Anna Atlante
}

Istituto di Biomembrane e Bioenergetica, CNR, Via Amendola 165/A, 70126 Bari, Italy

Correspondence should be addressed to Anna Atlante, a.atlante@ibbe.cnr.it

Received 14 April 2010; Revised 24 June 2010; Accepted 9 July 2010

Academic Editor: Gemma Casadesus

Copyright ( $\odot 2010$ Antonella Bobba et al. This is an open access article distributed under the Creative Commons Attribution License, which permits unrestricted use, distribution, and reproduction in any medium, provided the original work is properly cited.

In this paper, we discuss the interplay between beta-amyloid $(\mathrm{A} \beta)$ peptide, Tau fragments, oxidative stress, and mitochondria in the neuronal model of cerebellar granule neurons (CGNs) in which the molecular events reminiscent of $\mathrm{AD}$ are activated. The identification of the death route and the cause/effect relationships between the events leading to death could be helpful to manage the progression of apoptosis in neurodegeneration and to define antiapoptotic treatments acting on precocious steps of the death process. Mitochondrial dysfunction is among the earliest events linked to $\mathrm{AD}$ and might play a causative role in disease onset and progression. Recent studies on CGNs have shown that adenine nucleotide translocator (ANT) impairment, due to interaction with toxic $\mathrm{N}$-ter Tau fragment, contributes in a significant manner to bioenergetic failure and mitochondrial dysfunction. These findings open a window for new therapeutic strategies aimed at preserving and/or improving mitochondrial function.

\section{Introduction}

Alzheimer's disease $(\mathrm{AD})$ is a common neurodegenerative disorder characterized by altered processing of specific proteins, formation of neurofibrillary tangles, imbalance of redox homeostasis, and degeneration of synapses and neurons. Although the mechanism of neurodegeneration in $\mathrm{AD}$ is not clearly understood, several studies presently indicate that apoptosis might occur and contribute to AD onset and progression [1-5]. Though it remains to be determined whether true apoptosis is a necessary event in neurodegeneration, a growing number of studies support the activation of apoptosis in general, and caspases specifically, as an early event that contributes to neurodegeneration and promote the pathological hallmarks associate with $\mathrm{AD}$ [6].

Transgenic animal models have been useful tools to study $\mathrm{AD}$, but currently many of them do not fully replicate the cascade of amyloid deposition, neurofibrillary tangles, and neurodegeneration that characterize the human disease [7]. Thus, as far as the studies about $\mathrm{AD}$ are concerned, the lack of an animal model that sufficiently resembles this disease is the reason why research should still proceed along parallel lines: studies carried out in animal models should be integrated and correlated to ad hoc-devised neuronal models in which the identification of single molecular steps is made possible.

Rat cerebellar granule neurons (CGNs) are a neuronal model widely used to study events linking apoptosis and neurodegeneration $[8,9]$ due to the ease of CGN culture production, their high degree of cellular homogeneity, and the findings revealing that during the onset of apoptosis several molecular events reminiscent of $\mathrm{AD}$ are activated [10].

In this paper, the role of key players of the neuronal apoptotic process is discussed with particular attention to the results obtained in CGNs. The production, effect, and interplay of beta-amyloid (A $\beta)$, Tau protein and its fragments are discussed together with the action of these proteins on mitochondria, and this is integrated in the scenario of CGN apoptosis. 


\section{The Experimental Model of CGNs: A Useful Model to Elucidate Neurodegenerative Mechanism(s)}

CGNs survive and differentiate in vitro in the presence of depolarizing concentrations of $\mathrm{KCl}(25 \mathrm{mM})$ without additional need for neurotrophic factors [11]. The mechanism of action of $\mathrm{KCl}$ is still controversial but, generally, it is believed that the increase in intracellular $\mathrm{Ca}^{2+}$ concentration $[12,13]$ and the activation of mitogen-activated protein kinase (MAPK) [14] induced by depolarization are involved.

If the serum is removed, and the concentration of $\mathrm{KCl}$ is kept below depolarizing levels (K5), the majority of CGNs die by an apoptotic process [12]. Under these conditions, that are equivalent to in vivo deafferentation, neuronal death is initiated and follows a general scheme that has been extensively characterized in recent years (for a review see [15]). The production of reactive oxygen species (ROS) and nitric oxide (NO), the increase in proteasome, antioxidant enzyme, and nitric oxide synthase (NOS) activities, and release of cytochrome $c$ (cyt $c$ ) into the cytosol are some of the main events taking place soon after apoptosis induction in CGNs and for which a cause-effect relationship has been defined. In the early phase of apoptosis, ROS, NO, and cGMP production increases as well as the activities of antioxidant enzymes and NOS [16-20], as the cell's attempt to counteract the ongoing oxidative stress [18]. However, due to superoxide production, cyt $c$ is released into the cytosol where it carries out a triple function since it acts (i) as an antioxidant compound and an ROS scavenger, (ii) as a respiratory substrate which can generate the mitochondrial transmembrane potential, and (iii) as the activator of the caspase cascade [21-23]. As a consequence of both NO and superoxide anion production, an increase in the levels of nitrated proteins has been found in the late phase (ranging from 3 to 15 hours after apoptosis induction) [19]. With apoptosis progression, the oxidative damage proceeds, antioxidant enzymes are inactivated by caspases and proteasome $[18,24]$, and, at the mitochondrial level, the adenine nucleotide translocator (ANT) is progressively impaired thus contributing to the transition pore opening in the late phase of the death process $[25,26]$.

Furthermore, it has been demonstrated that during the onset of apoptosis of CGNs, several molecular events reminiscent of $\mathrm{AD}$ are induced. An amyloidogenic process is activated with an increased production of $\mathrm{A} \beta$ which initiates a sort of autocrine toxic loop [27]. Contextually to the increase in $A \beta$ deposition, Tau protein, which is the main constituent of $\mathrm{AD}$ neurofibrillary tangles, is cleaved by the concerted action of calpain and caspases with the production of toxic fragments $[28,29]$. The mechanism of action of a Tau toxic fragment has been elucidated, and ANT has been identified as the specific mitochondrial target of such fragment [30].

\section{Formation of $A \beta$ and Tau Protein Fragments in AD}

One of the central points in the physiopathology of $\mathrm{AD}$ is the altered function and/or structure of two "Alzheimer's proteins," namely the amyloid precursor protein (APP) and Tau.

APP is a membrane glycoprotein, which undergoes complex intracellular trafficking. The biological function of APP is still not fully clear. Roles in cell adhesion, neuronal migration, cell proliferation, neurite outgrowth, axonal transport, neuroprotection, and signal transduction have been proposed [31]. The abnormal cleavage of APP leads to the production of $A \beta$ which is the main component of senile plaques in $\mathrm{AD}$ and per se can induce neuronal cell death.

Tau is a neuron-specific microtubule-associated protein and a critical component of the neuronal cytoskeleton which progressively disaggregates during apoptosis. The proper function of Tau depends upon a precise equilibrium between different isoforms and its state of phosphorylation. In $\mathrm{AD}$, as well as in other human dementias, Tau undergoes a series of posttranslational changes including abnormal phosphorylation, glycosylation, glycation, and truncation (see [32]), which may render Tau more prone to form aggregated structures, the neurofibrillary tangles, which constitute a major hallmark of AD. Following such aggregation, the microtubules disintegrate, collapsing the neuron's transport system, with consequent altered communication between neurons, eventually ending in cell death.

Interestingly, in the experimental model of CGNs, it has been proposed that Tau and APP form a complex in vivo via the adaptor protein Fe65 [33] which is abundantly expressed in the central nervous system of mammals and in particular in the cerebellum and hippocampus [34]. As a consequence, the full-length Tau can play a role in regulating the proper localization of APP and of its partners. During apoptosis, the disruption of the Tau-Fe65 interaction leads to a mislocalization of the APP-Fe65 complex within the cell that in turn could induce a change in the proteolytic fate of both APP and Tau proteins (Figure 1).

As far as $\mathrm{A} \beta$ production is concerned, it has been reported that in the commitment phase (6 hours) of CGN apoptosis, an amyloidogenic process is activated which rapidly and irreversibly leads to increased production of $\mathrm{A} \beta$ [27]. $\mathrm{A} \beta$ may be released outside the cell and act as a soluble and diffusible apoptotic death mediator, affecting neighbouring healthy neurons and activating a toxic loop that further accelerates and propagates the process of neurodegeneration. Accordingly, it has been found that coincubation of CGN apoptotic cultures with antibodies directed against A $\beta$ significantly slows down the extension of cell death and quantitatively increases the neuronal survival rate [27]. Studies carried out on CGNs as well as on various cell models indicate that both nonaggregated and, to a greater extent, aggregated $\mathrm{A} \beta$ peptides of the short toxic fragment A $\beta 25-35$ can induce apoptosis when externally added to cell cultures $[35,36]$ and that different $A \beta$ aggregation forms (monomers, protofibrillar intermediate, and mature fibrils) can have diverse effects [37-39].

In the same experimental model (i.e., CGNs), A $325-35-$ induced apoptosis has been found to be associated with the activation of multiple executioner caspases (caspases-2, -3, and -6) [40], and the shorter $\mathrm{A} \beta$ fragment $(\mathrm{A} \beta 31-35)$ is able to induce neurodegeneration with an early increase in 


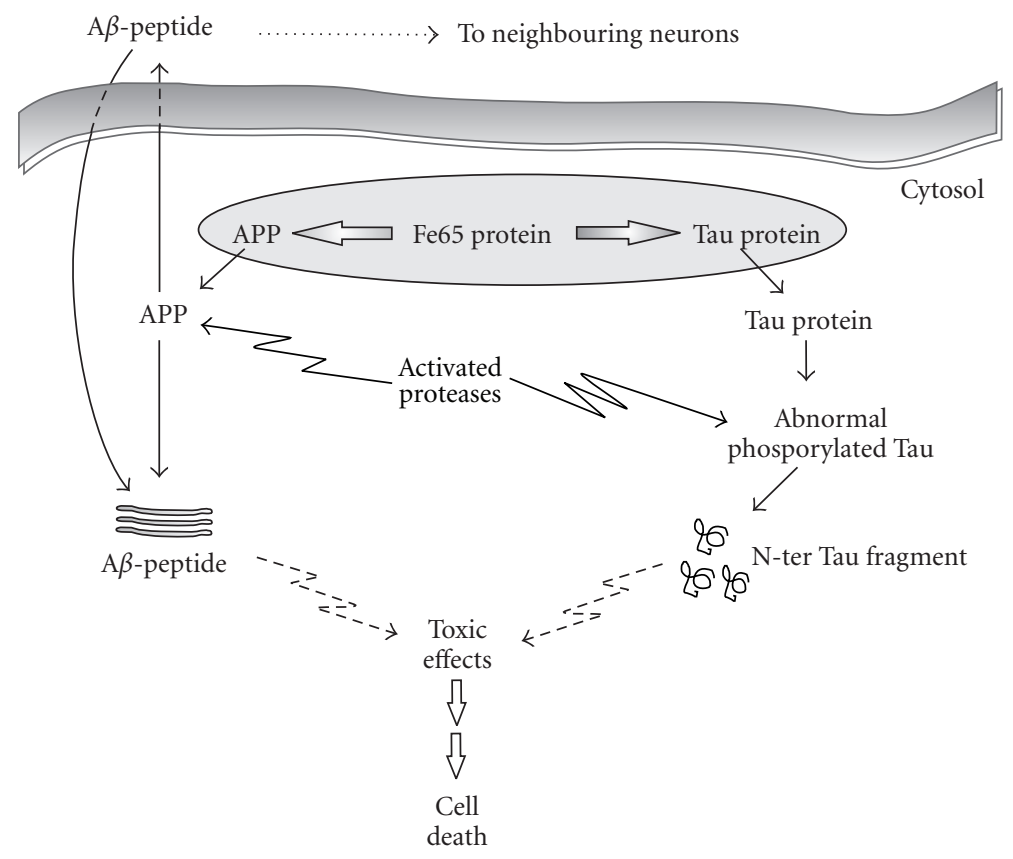

Figure 1: Schematic overview of $\mathrm{A} \beta$ peptide and Tau fragments production in CGNs. A $\beta$ is produced intracellularly or taken up from extracellular sources and together with Tau fragments has various pathological effects on cell function.

bax mRNA level followed by delayed caspase- 3 activation [41]. Finally, it has been reported that $\mathrm{A} \beta$ may interfere with $\mathrm{K}^{+}$channel trafficking $[42,43]$, altering $\mathrm{K}^{+}$currents and therefore causing an increase in cell death as a result of a decrease in cytoplasmic $\mathrm{K}^{+}$concentrations. Consistently, the selective upregulation of the expression of two voltagedependent potassium channel subunits (Kv4.2 and Kv4.3) has been found in CGNs after $\mathrm{A} \beta 25-35$ exposure [44].

In CGNs, contextually to the significant increase in amyloidogenic metabolism of APP, Tau also undergoes posttranslational modifications. As soon as 6 hours after apoptosis induction, a change in Tau phosphorylation state occurs in concomitance with caspase and calpain-mediated cleavages (Figure 1). As a consequence, several fragments of Tau protein are produced during apoptosis, the most abundant of which is a $17 \mathrm{kDa}$ residual fragment, probably located at the $\mathrm{NH}_{2}$-terminus of Tau, which is unable to bind to microtubules and is diagnostic for the ongoing apoptotic process [28].

Truncated forms of Tau, besides being produced during apoptosis, can also be effectors of apoptosis by themselves and operate as toxic fragments that further induce cell death so contributing to the progression of neurodegeneration by an "autocatalytic process" [29, 45-47]. Both C-ter and $\mathrm{N}$-ter Tau fragments have been analyzed for their neurotoxicity. While the microtubule-binding capacity of the Cter fragment is well documented, relatively little is known about the function of the N-terminal domain. Transfection of neuronal cells with C-terminal Tau fragments induces cell death $[46,47]$ while exogenous overexpression of $\mathrm{N}$ ter Tau fragments in CGNs can be either neuroprotective or neurotoxic depending on its length [29]. The long N-ter Tau fragment (1-230) is antiapoptotic and promotes the prosurvival effect of the AKT pathway. On the other hand, the short $\mathrm{N}$-ter Tau fragment (1-44) exerts a toxic action involving glutamate receptors. Moreover, further analysis performed in the CGN model system further narrowed the extent of the aminoacid stretch which is toxic to the cells, and the $\mathrm{N}$ ter-26-44 Tau fragment was found to be the minimal active moiety which retained a marked neurotoxic effect. On the other hand, the $\mathrm{NH}_{2}-1-25$ Tau fragment was inactive [48].

\section{4. $A \beta$ and $\mathbf{N}$-ter Tau Fragments Interaction with Mitochondria}

Mounting evidence indicates that mitochondrial dysfunction occurs early in $\mathrm{AD}$, worsens with clinical deterioration, and is associated with impairment of energy homeostasis; deficit in the function of complexes of the respiratory chains reduced ATP synthesis as well as altered mitochondrial structure [4951]. Consistently, a reduced activity of the cytochrome $c$ oxidase (Complex IV of respiratory chain) has been reported in different brain regions [51] as well as in platelets [52] and fibroblasts [53] of AD patients, but the involvement of other mitochondrial oxidative phosphorylation complexes is less documented and more controversial. Cardoso and collaborators [54] found a decreased ATP level in AD cybrids, and other authors report that the activity of Complex IV, but not the activity of F1F0-ATPase (Complex V), decreases in the hippocampus and platelets of $\mathrm{AD}$ cases $[55,56]$. Because mitochondria are the powerhouse of cells, damage to mitochondria, such as impairment of Complex IV activity, could have functional consequences on energy metabolism [56]. 


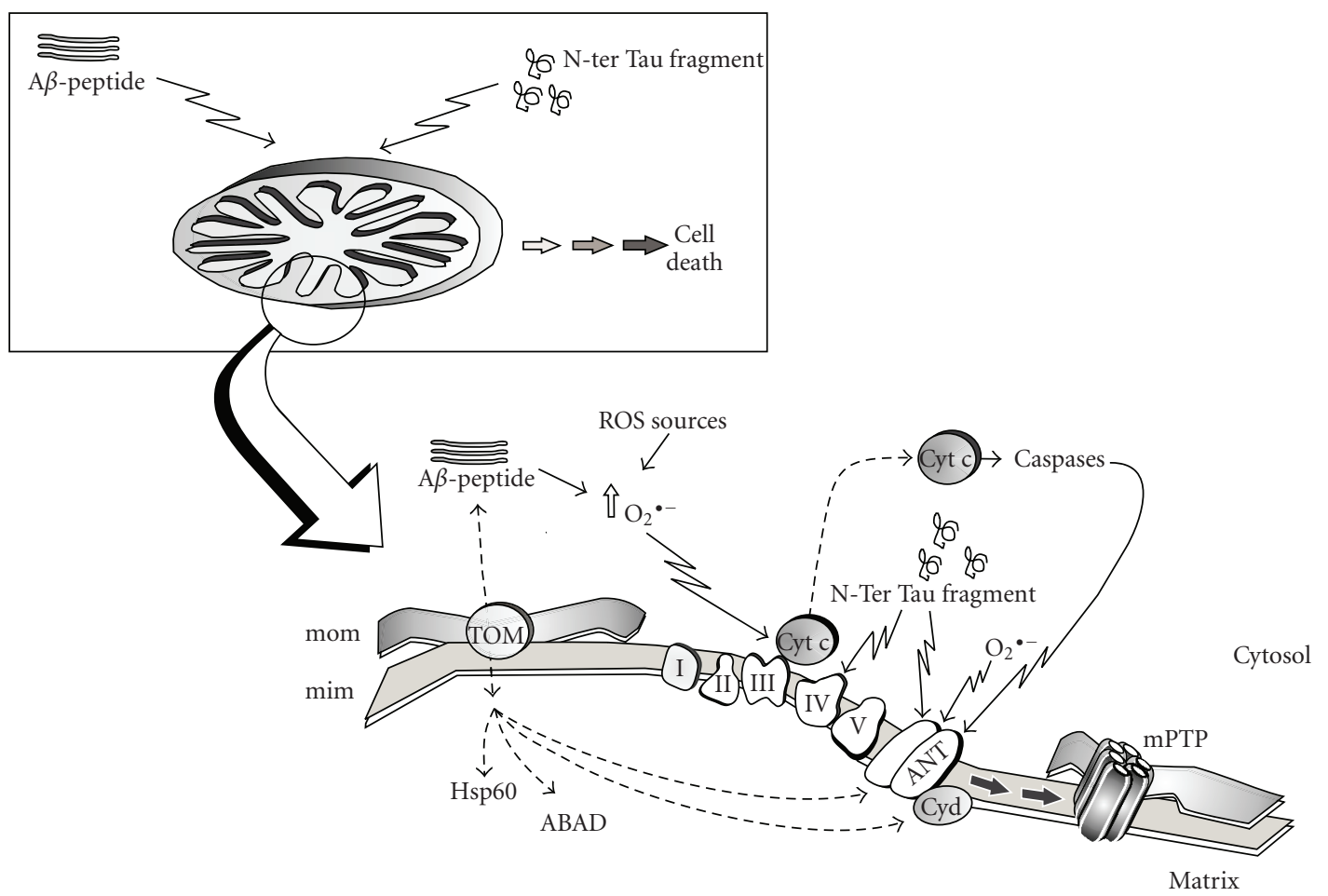

FIgURE 2: Proposed mechanism of A $\beta$ peptide and N-ter Tau fragment interaction with mitochondria; for further details see text. mom, mitochondrial outer membrane; $\mathrm{mim}$, mitochondrial inner membrane; TOM, translocase of the outer membrane; $I-V$, respiratory chain complexes; $c y t c$, cytochrome $c$; ANT, adenine nucleotide translocator; $C y D$, cyclophilin $\mathrm{D} ; m P T P$, mitochondrial permeability transition pore.

Furthermore, mitochondrial dysfunction has been proposed to be the link between the histopathological hallmarks of $\mathrm{AD}$, caused by $\mathrm{A} \beta$ and Tau deposition, and neuronal and synaptic loss [57]. The emerging picture is one in which, at the level of mitochondria, both Alzheimer's proteins exhibit synergistic effects finally leading to the acceleration of neurodegenerative mechanisms (Figure 2).

As far as $\mathrm{A} \beta$ is concerned, although the classical view is that $A \beta$ is deposited extracellularly, both cellular and biochemical studies carried out in different models of $\mathrm{AD}$ and aging have provided evidence that this peptide can also accumulate inside neurons, target mitochondria, and contribute to disease progression [58-61]. By using in vivo and in vitro approaches, it has been demonstrated that $\mathrm{A} \beta$ is transported into rat mitochondria via the translocase of the outer membrane (TOM) [62] and localizes within the mitochondrial cristae. A similar distribution pattern of $\mathrm{A} \beta$ in mitochondria has been shown by immunoelectron microscopy in human cortical brain biopsies [62].

Interaction of $\mathrm{A} \beta$ with mitochondria could be considered a general route common to different cell types since both in dividing cells (i.e., neuroblastoma cells) and in terminally differentiated neurons (i.e., primary neuronal cultures), either extracellulary applied or secreted $A \beta$ can be internalized, and it colocalizes with mitochondrial markers $[62,63]$ (Figure 2). Interaction of $A \beta$ with the matrix protein ABAD (amyloid-binding alcohol dehydrogenase) has been described [64], whereas Caspersen et al. [65] reported that in mouse and human brain samples from $\mathrm{AD}$ patients, $\mathrm{A} \beta$ colocalizes with the mitochondrial matrix protein Hsp60. Recent biochemical studies imply that the formation of the mitochondrial permeability transition pore ( $\mathrm{mPTP})$ is involved in $\mathrm{A} \beta$-mediated mitochondrial dysfunction [66], and by using a computational approach and predictive analysis tools, it has been hypothesized that $\mathrm{A} \beta$ can strongly interact in the inner membrane with ANT and Cyclophilin $\mathrm{D}$, two components of the MPTP [67].

A connection between Tau protein and mitochondria has recently been proposed; by overexpressing the N-ter Tau fragment truncated at Asp-421 to mimic caspase cleavage in immortalized neurons, it was possible to induce mitochondrial fragmentation and elevated oxidative stress levels [68].

To the best of our knowledge, the toxicity of N-ter Tau fragments on mitochondria has been deeply investigated only in the CGN model system and has been found to involve a mitochondrial dysfunction with impairment of oxidative phosphorylation [30] (Figure 2). Both Complex IV and ANT proved to be targets of the short $\mathrm{NH}_{2}-26-44$ Tau fragment, but ANT is the only mitochondrial target responsible for the impairment of oxidative phosphorylation. Detailed biochemical studies have revealed that inhibition of ANT is noncompetitive, suggesting that the $\mathrm{NH}_{2}-26-44$ Tau fragment does not interact with the catalytic site but with some other site of the enzyme which could distort the enzyme structure thus also affecting the catalytic binding site.

This finding is consistent with the picture of the apoptotic process in CGN that to date has been built up: in late apoptosis, a noncompetitive-like inhibition of ANT has been 


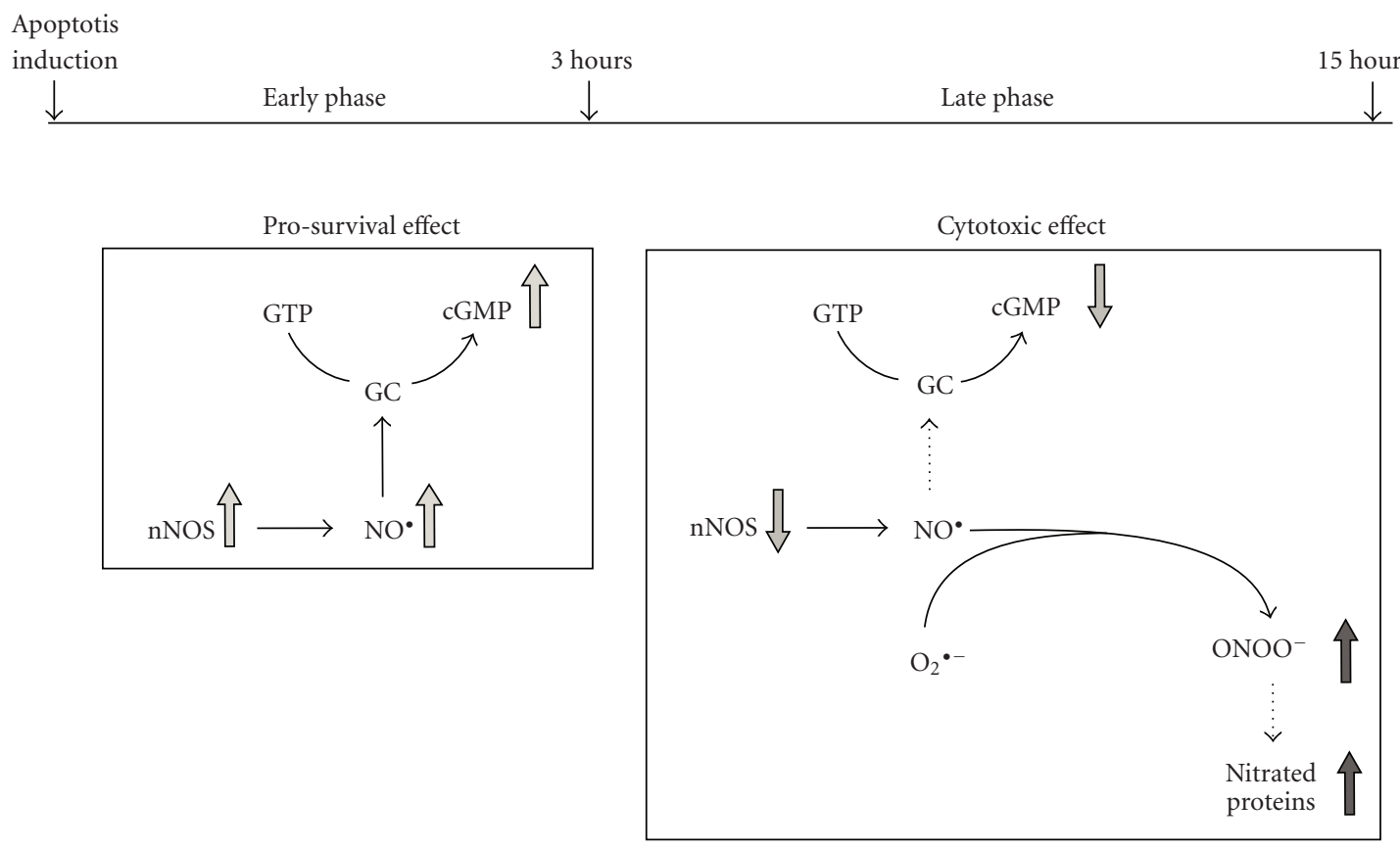

FIGURE 3: Schematic representation of the time-dependent, dual role of nitric oxide in CGN apoptosis; see text for details. GC, guanylil cyclase; $c G M P$, cyclic GMP; $n N O S$, neuronal nitric oxide synthase; $\mathrm{O}_{2}{ }^{\cdot-}$, superoxide anion; $\mathrm{ONOO}^{-}$, peroxynitrite.

found, probably due to caspase activity [26], but it is not dependent on a direct caspase-ANT interaction. However since $\mathrm{NH}_{2}-26-44$ Tau fragment is likely to be generated during apoptosis given that the N-terminal domain of Tau contains consensus sequences suitable for cleavage by caspase(s) [28, 45], which are activated in apoptotic degenerating neurons in $\mathrm{AD}[69,70]$, the possibility exists that caspase(s) gradually inhibit/s ANT as a result of $\mathrm{NH}_{2}$-Tau cleavage and the generation of toxic $\mathrm{NH}_{2}-26-44$ Tau fragment. In this case, $\mathrm{NH}_{2}-26-44$ Tau fragment should directly bind ANT.

\section{Nitric Oxide and AD: Interplay between Alzheimer's Proteins, Nitrosative/Oxidative Stress, and Mitochondria}

NO produced by NOS, is a molecule endowed with a double role acting as either a prosurvival or a toxic molecule. As a prosurvival molecule, $\mathrm{NO}$ plays a role in cell signaling in the nervous system and in synaptic plasticity $[71,72]$, and it may be involved in diverse biological functions acting through either cGMP-dependent or -independent pathways.

When the role of the NO/NOS system was investigated in CGNs, it was found that NO exerts its dual and opposite effects on the neurodegenerative process, depending on the time after induction of apoptosis (Figure 3 ). In an early phase, up to $3 \mathrm{~h}$ of apoptosis, there is an increase in the expression of the neuronal isoform of NOS (nNOS) as well as in the production of $\mathrm{NO}$, which in turn supports the survival of CGNs through a cGMP-dependent mechanism.

Consistently with these results, it has also been reported that: (i) NO may be responsible for neuroprotection during
$\mathrm{A} \beta$-induced cell death $[73,74]$, (ii) low concentration of NO produced by a healthy cerebrovascular endothelium was found to influence the parenchymal brain cells in a protective way [75], and (iii) in cultured human neuroblastoma cells, low concentrations of NO upregulate the expression of alpha-secretase, while downregulating that of beta-secretase, suggesting that, in the relative absence of superoxide, cerebrovascular NO might act to suppress brain production of $\mathrm{A} \beta[76]$.

On the other hand, sustained generation of NO has been implicated in the cellular death occurring in different neurodegenerative diseases as well as in $\mathrm{AD}$ [77]. As far as the experimental system of CGNs is concerned (Figure 3 ), it was found that, in the late phase of the apoptotic program, after $3 \mathrm{~h}$, nNOS expression and activity decreased, resulting in the shut down of NO and cGMP production, and the toxic role of nitric oxide prevailed due to the reaction with superoxide anions to produce peroxynitrite $\left(\mathrm{ONOO}^{-}\right)$which in turn is able to induce neuronal injury mainly through nitration of tyrosine residues in cellular proteins, whose level increases. These events together with other apoptotic events already described in this cell model $[15,23,25,26]$ would commit these cells irreversibly to death.

Thus, it can be assumed that once accumulated inside the cell, NO can play different roles, depending on its level, cell context, and amount of superoxide anion. In Figure 4, a general picture is shown which takes into account the main findings on the involvement of nitrosative stress in the neurodegenerative process. In brains from $\mathrm{AD}$ patients, an early and striking upregulation of all three isoforms of NOS has been reported $[78,79]$. This finding is further supported by experimental data obtained in different systems, ranging 


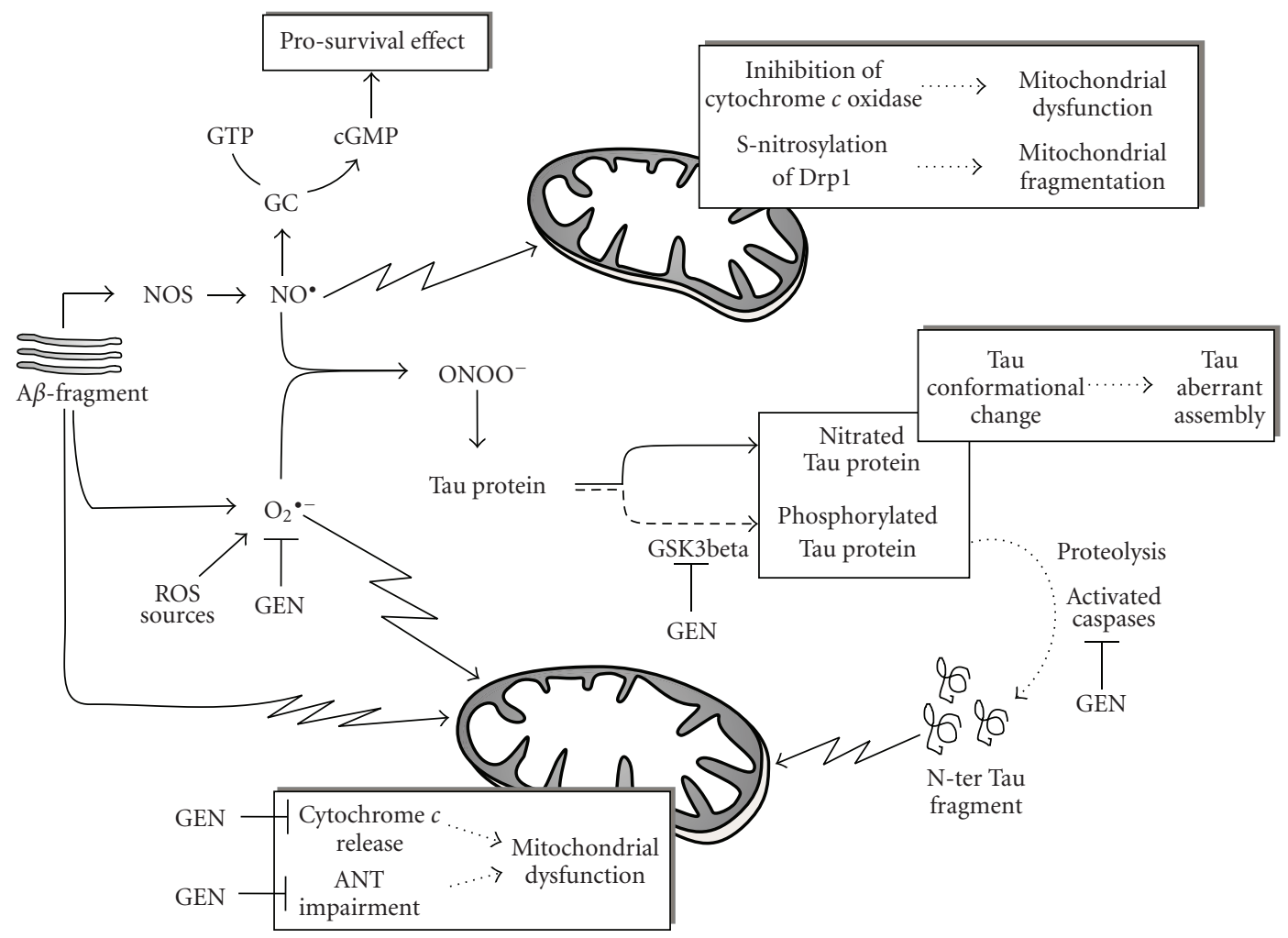

Figure 4: Schematic overview of the interplay between $\mathrm{A} \beta$, Tau, oxidative/nitrosative stress, and mitochondria; see text for details. GC, guanylil cyclase; $c G M P$, cyclic GMP; NOS, nitric oxide synthase; $\mathrm{O}_{2}{ }^{--}$, superoxide anion; $\mathrm{ONOO}^{-}$, peroxynitrite; ANT, adenine nucleotide translocator; GSK3beta, glycogen synthase kinase-3beta; GEN, Genistein.

from in vivo animals to cell lines, which indicates that NO is responsible for $\mathrm{A} \beta$ toxicity and highlights a link between $\mathrm{NO} / \mathrm{NOS}$ level and $\mathrm{A} \beta$-induced brain dysfunction $[80,81]$. Activation of the neuronal isoform of NOS (nNOS) [82] and an increased production of $\mathrm{NO}$ [83] were also found in rat cerebral cortex and hippocampus after intracerebroventricular administration of A $\beta 25-30$ and in APP-transfected cells, respectively.

In an early phase, NO could induce a cGMP-mediated prosurvival signaling pathway in an attempt to counteract the ongoing neurodegenerative process $[19,84]$. However, NO can also directly trigger mitochondrial dysfunction, a process which is believed to play a causative role in $\mathrm{AD}$ onset and progression. Indeed it has been reported that NO both induces a bioenergetic failure, with impairment in the function of Complex IV [85], and triggers mitochondrial fission/fragmentation thus causing cell death in primary culture of cortical neurons [86, 87]. S-nitrosylation, a covalent redox reaction of $\mathrm{NO}$ with specific protein thiol groups, could be one mechanism contributing to the NOinduced mitochondrial fragmentation. Accordingly, it has been reported that in $\mathrm{AD}$ patients and animal model, NO induces S-nitrosylation of dynamin-related protein 1 (Drp1), a protein specifically involved in mitochondrial fission [88, 89]. On the other hand, Bossy et al. [90] found that NO can also induce Drp1 inactivation by increasing its phosphorylation. Although there are no data on the involvement of Drp1 in the CGN model, it has been recently reported that mitochondrial fragmentation occurs as an early event in response to injury in CGNs, and increased activation of mitofusin 2 (Mfn2), a protein involved in mitochondrial fusion, blocks mitochondrial fragmentation and protects neurons against cell death [91, 92].

In addition to NO, oxidative damage has been reported in aging and age-related neurodegenerative diseases, including $\mathrm{AD}[93,94]$, and superoxide anion production has been induced by $\mathrm{A} \beta$-treatment in neurons $[95,96]$. It is known that in the course of neurodegeneration, the superoxide anion can act directly on mitochondria thus inducing cyt $c$ release and precocious impairment of ANT (see [18] and references therein).

On the other hand, NO readily reacts with superoxide anions to form the strong oxidant $\mathrm{ONOO}^{-}$which in turn induces protein nitration. Consistently, an increase in protein nitration has been found in brain tissue from cases of $\mathrm{AD}$ which correlates with neurodegeneration [97]. Tau protein can also undergo a $\mathrm{ONOO}^{-}$-mediated process, and nitration of the Tyr29 residue has been proposed as a specific diseaserelated event [98]. Furthermore, peroxynitrite can also induce $\mathrm{AD}$-like Tau hyperphosphorylation via activation of both glycogen synthase kinase-3beta (GSK3beta) and p38 MAPKs [99].

Nitration, as well as phosphorylation, of Tau protein induces conformational changes that facilitate aberrant Tau 
assembly. Consistently, it has been reported that nitrated Tau is colocalized with neurofibrillary tangle in AD brain, shows a significantly decreased binding activity to microtubules, and is involved in the formation of filamentous Tau inclusions [100]. In these conditions, Tau fragmentation might occur, and $\mathrm{N}$-ter Tau fragments, together with $\mathrm{A} \beta$ and superoxide, can further decrease mitochondrial efficiency thus contributing to mitochondrial dysfunction.

\section{Implication of Genistein on Preventing $A \beta$ and Tau Toxicity}

The main goal in $\mathrm{AD}$ treatment is focused on a preventive approach. Treatment of declared AD with any compounds may have either a poor effect due to the severe neuronal death occurring in $\mathrm{AD}$ or a questionable risk/benefit ratio such as in the case of estrogen. In this regard, estrogen has been shown to block $A \beta$-induced neuronal cell death in several studies thus suggesting that estradiol replacement therapy should show improvement in patients with $\mathrm{AD}$ [101]. However, the efficiency of estradiol in the treatment of $\mathrm{AD}$ has been seriously questioned due to its fourth unwanted side effect, that is, proliferative and oncogenic effects on nonneuronal cells [102].

A clear point emerging from the bulk of studies dealing with $\mathrm{AD}$ etiopathology is that all factors involved in $\mathrm{AD}$ are associated with oxidative stress [103]. In the light of this, natural oxidants have recently received much attention as promising agents for reducing the risk of oxidative stressrelated diseases. Among them genistein received a lot of attention.

Genistein (4'.5.7-trihydroxyisoflavone) is the most active compound of soy isoflavones, the one which reaches the highest concentration in human blood [104], possesses an antioxidant activity, shows an affinity to estrogen receptors, thus acting as an estrogen-like compound but without the negative effects of estrogens, and is able to cross the bloodbrain barrier (see [105]).

There is considerable literature about the effect of genistein on the progression of neurodegeneration. It has been reported that in the nervous system, isoflavones attenuate primary neuronal apoptosis by activating estrogen receptors [106] and genistein is able both to suppress A $\beta 25-35-$ induced ROS overproduction in isolated rat brain synaptosomes [107] and to increase cell viability in cooperation with other trophic factor such as folic acid in cortical neurons [108]. Consistently, Zeng et al. [105] describe the protective effect of genistein on cultured hippocampal neurons against $\mathrm{A} \beta$-induced apoptosis and have demonstrated that genistein inhibits the elevation of intracellular free $\mathrm{Ca}^{2+}$, the production of oxidant free radicals caused by $\mathrm{A} \beta 25-35$, the DNA fragmentation, and the activation of caspase- 3 , thus suggesting that genistein acts upstream of caspase- 3 to block apoptosis (Figure 4).

Genistein may also decrease the hyperphosphorylation of Tau protein by inactivating GSK3beta, the kinase involved in Tau phosphorylation in homocysteine-mediated neurodegeneration in SH-SY5Y human neuroblastoma cells [109].
Recently, in CGNs undergoing apoptosis, the effect of genistein was studied at subcellular level and for the first time at mitochondrial level [110]. Genistein and to a lesser extent its analogue daidzein, both used at dietary concentrations, can prevent low potassium-dependent apoptosis in CGNs by reducing the impairment of both aerobic glucose metabolism and mitochondrial uncoupling, two processes occurring in CGN apoptosis [16]. Furthermore, genistein is also able to prevent cyt $c$ release, ANT alteration, and mPTP opening; that is, some steps of the mitochondrial pathway to apoptosis that are somehow related to the ROS production which takes place during apoptosis.

Thus, since both genistein and daidzein have been proved to decrease ROS levels, it has been suggested that the prevention of apoptosis is essentially due to the antioxidant properties of these flavonoids [110]. Nonetheless, the effect of genistein proved to be rather specific since other flavonoids such as catechin and epicatechin failed to prevent CGN death in spite of their shared antioxidant capability.

Consistently, genistein also abolishes neuronal ROS production induced by $A \beta$ administration to primary culture of cortical neurons [111] and enhances the activities of other antioxidant molecules and enzymes (superoxide dismutase, glutathione peroxidase and reductase) both in vitro and in vivo $[112,113]$.

\section{Conclusions}

The etiology of Alzheimer's disease is complex and not fully elucidated. On the other hand, it is important to develop a better understanding of the different biochemical pathways, their role, and their link with the amyloid hypothesis in $\mathrm{AD}$, since it may lead to the development of more effective treatment strategies for this disease. It seems clear then that promising developments as for the prevention and/or delay of the onset of $\mathrm{AD}$ can be derived from definition of antiapoptotic treatments acting on the precocious steps of the death process, such as blockade of generation of reactive oxygen species and implementation of the NO prosurvival signaling pathway that, although not able to fully prevent the disease, can at least delay onset or reduce the severity of neurodegeneration. In this regard, genistein and its analogue daidzein may perhaps be of use in neuroprotection. Furthermore, the knowledge emerging from studies conducted on CGNs, that ANT impairment contributes in a significant manner to bioenergetic failure and mitochondrial dysfunction in the course of neurodegeneration, may open a window for new therapeutic strategies aimed at preserving and/or improving mitochondrial function, representing an exciting challenge for biochemists. More studies are required to determine whether phytoestrogens, protease inhibitors and mitochondrial-targeted compounds could fulfill these expectations.

\section{Acknowledgment}

The authors thank Mr. Richard Lusardi for linguistic consultation. 


\section{References}

[1] M. P. Mattson, "Neuronal life-and-death signaling, apoptosis, and neurodegenerative disorders," Antioxidants \& Redox Signaling, vol. 8, no. 11-12, pp. 1997-2006, 2006.

[2] C. Culmsee and S. Landshamer, "Molecular insights into mechanisms of the cell death programml: role in the progression of neurodegenerative disorders," Current Alzheimer Research, vol. 3, no. 4, pp. 269-283, 2006.

[3] A. Nunomura, P. I. Moreira, H. G. Lee et al., "Neuronal death and survival under oxidative stress in Alzheimer and Parkinson diseases," CNS \& Neurological Disorders-Drug Targets, vol. 6, no. 6, pp. 411-423, 2007.

[4] L. S. Honig and R. N. Rosenberg, "Apoptosis and neurologic disease," The American Journal of Medicine, vol. 108, no. 4, pp. 317-330, 2000.

[5] A. Eckert, C. A. Marques, U. Keil, K. Schüssel, and W. E. Müller, "Increased apoptotic cell death in sporadic and genetic Alzheimer's Disease," Annals of the New York Academy of Sciences, vol. 1010, pp. 604-609, 2003.

[6] T. T. Rohn and E. Head, "Caspase activation in Alzheimer's disease: early to rise and late to bed," Reviews in the Neurosciences, vol. 19, no. 6, pp. 383-393, 2008.

[7] C. Schwab, M. Hosokawa, and P. L. McGeer, "Transgenic mice overexpressing amyloid beta protein are an incomplete model of Alzheimer disease," Experimental Neurology, vol. 188, no. 1, pp. 52-64, 2004.

[8] N. Canu and P. Calissano, "In vitro cultured neurons for molecular studies correlating apoptosis with events related to Alzheimer disease," Cerebellum, vol. 2, no. 4, pp. 270-278, 2003.

[9] P. Calissano, C. Matrone, and G. Amadoro, "Apoptosis and in vitro Alzheimer disease neuronal models," Communitative \& Integrative Biology, vol. 2, no. 2, pp. 163-169, 2009.

[10] S. Cicconi, A. Gentile, M. T. Ciotti, T. Parasassi, A. Serafino, and P. Calissano, "Apoptotic death induces A $\beta$ production and fibril formation to a much larger extent than necroticlike death in CGNs," Journal of Alzheimer's Disease, vol. 12, no. 3, pp. 211-220, 2007.

[11] V. Gallo, M. T. Ciotti, F. Aloisi, and G. Levi, "Developmental features of rat cerebellar neural cells cultured in a chemically defined medium," Journal of Neuroscience Research, vol. 15, no. 3, pp. 289-301, 1986.

[12] S. R. D’Mello, C. Galli, T. Ciotti, and P. Calissano, "Induction of apoptosis in cerebellar granule neurons by low potassiumml: inhibition of death by insulin-like growth factor I and cAMP," Proceedings of the National Academy of Sciences of the United States of America, vol. 90, no. 23, pp. 10989-10993, 1993.

[13] C. Galli, O. Meucci, A. Scorziello, T. M. Werge, P. Calissano, and G. Schettini, "Apoptosis in cerebellar granule cells is blocked by high $\mathrm{KCl}$, forskolin, and IGF-1 through distinct mechanisms of action: the involvement of intracellular calcium and RNA synthesis," Journal of Neuroscience, vol. 15, no. 2, pp. 1172-1179, 1995.

[14] L. B. Rosen, D. D. Ginty, M. J. Weber, and M. E. Greenberg, "Membrane depolarization and calcium influx stimulate MEK and MAP kinase via activation of Ras," Neuron, vol. 12, no. 6, pp. 1207-1221, 1994.

[15] A. Bobba, A. Atlante, L. de Bari, S. Passarella, and E. Marra, "Apoptosis and cytochrome $c$ release in cerebellar granule cells," In Vivo, vol. 18, no. 3, pp. 335-344, 2004.
[16] A. Atlante, S. Gagliardi, E. Marra, and P. Calissano, "Neuronal apoptosis in rats is accompanied by rapid impairment of cellular respiration and is prevented by scavengers of reactive oxygen species," Neuroscience Letters, vol. 245, no. 3, pp. 127-130, 1998.

[17] A. Atlante and S. Passarella, "Detection of reactive oxygen species in primary cultures of cerebellar granule cells," Brain Research Protocols, vol. 4, no. 3, pp. 266-270, 1999.

[18] A. Atlante, A. Bobba, P. Calissano, S. Passarella, and E. Marra, "The apoptosis/necrosis transition in cerebellar granule cells depends on the mutual relationship of the antioxidant and the proteolytic systems which regulate ROS production and cytochrome $c$ release en route to death," Journal of Neurochemistry, vol. 84, no. 5, pp. 960-971, 2003.

[19] A. Bobba, A. Atlante, L. Moro, P. Calissano, and E. Marra, "Nitric oxide has dual opposite roles during early and late phases of apoptosis in cerebellar granule neurons," Apoptosis, vol. 12, no. 9, pp. 1597-1610, 2007.

[20] A. Bobba, A. Atlante, V. A. Petragallo, and E. Marra, "Different sources of reactive oxygen species contribute to low potassium-induced apoptosis in cerebellar granule cells," International Journal of Molecular Medicine, vol. 21, no. 6, pp. 737-745, 2008.

[21] A. Atlante, P. Calissano, A. Bobba, A. Azzariti, E. Marra, and S. Passarella, "Cytochrome $\mathrm{c}$ is released from mitochondria in a reactive oxygen species (ROS)-dependent fashion and can operate as a ROS scavenger and as a respiratory substrate in cerebellar neurons undergoing excitotoxic death," Journal of Biological Chemistry, vol. 275, no. 47, pp. 37159-37166, 2000.

[22] A. Atlante, L. De Bari, A. Bobba, E. Marra, P. Calissano, and S. Passarella, "Cytochrome $c$, released from cerebellar granule cells undergoing apoptosis or excytotoxic death, can generate protonmotive force and drive ATP synthesis in isolated mitochondria," Journal of Neurochemistry, vol. 86, no. 3, pp. 591-604, 2003.

[23] A. Bobba, A. Atlante, S. Giannattasio, G. Sgaramella, P. Calissano, and E. Marra, "Early release and subsequent caspase-mediated degradation of cytochrome $c$ in apoptotic cerebellar granule cells," FEBS Letters, vol. 457, no. 1, pp. 126130, 1999.

[24] A. Bobba, N. Canu, A. Atlante, V. Petragallo, P. Calissano, and E. Marra, "Proteasome inhibitors prevent cytochrome c release during apoptosis but not in excitotoxic death of cerebellar granule neurons," FEBS Letters, vol. 515, no. 1-3, pp. 8-12, 2002.

[25] A. Atlante, S. Giannattasio, A. Bobba et al., "An increase in the ATP levels occurs in cerebellar granule cells en route to apoptosis in which ATP derives from both oxidative phosphorylation and anaerobic glycolysis," Biochimica et Biophysica Acta, vol. 1708, no. 1, pp. 50-62, 2005.

[26] A. Atlante, A. Bobba, L. de Bari et al., "Caspase-dependent alteration of the ADP/ATP translocator triggers the mitochondrial permeability transition which is not required for the low-potassium-dependent apoptosis of cerebellar granule cells," Journal of Neurochemistry, vol. 97, no. 4, pp. 11661181, 2006.

[27] C. Galli, A. Piccini, M. T. Ciotti et al., "Increased amyloidogenic secretion in cerebellar granule cells undergoing apoptosis," Proceedings of the National Academy of Sciences of the United States of America, vol. 95, no. 3, pp. 1247-1252, 1998. 
[28] N. Canu, L. Dus, C. Barbato et al., "Tau cleavage and dephosphorylation in cerebellar granule neurons undergoing apoptosis," Journal of Neuroscience, vol. 18, no. 18, pp. 70617074, 1998.

[29] G. Amadoro, A. L. Serafino, C. Barbato et al., "Role of Nterminal tau domain integrity on the survival of cerebellar granule neurons," Cell Death \& Differentiation, vol. 11, no. 2, pp. 217-230, 2004.

[30] A. Atlante, G. Amadoro, A. Bobba et al., "A peptide containing residues 26-44 of tau protein impairs mitochondrial oxidative phosphorylation acting at the level of the adenine nucleotide translocator," Biochimica et Biophysica Acta, vol. 1777, no. 10, pp. 1289-1300, 2008.

[31] E. H. Koo, "The $\beta$-amyloid precursor protein (APP) and alzheimer's disease: does the tail wag the dog?" Traffic, vol. 3, no. 11, pp. 763-770, 2002.

[32] M. Goedert, M. G. Spillantini, R. Jakes, D. Rutherford, and R. A. Crowther, "Multiple isoforms of human microtubuleassociated protein tau: sequences and localization in neurofibrillary tangles of Alzheimer's disease," Neuron, vol. 3, no. 4, pp. 519-526, 1989.

[33] C. Barbato, N. Canu, N. Zambrano et al., "Interaction of Tau with Fe65 links tau to APP," Neurobiology of Disease, vol. 18, no. 2, pp. 399-408, 2005.

[34] S. Kesavapany, S. J. Banner, K.-F. Lau et al., "Expression of the Fe65 adapter protein in adult and developing mouse brain," Neuroscience, vol. 115, no. 3, pp. 951-960, 2002.

[35] A. Scorziello, O. Meucci, T. Florio et al., " $\beta 25-35$ alters calcium homeostasis and induces neurotoxicity in cerebellar granule cells," Journal of Neurochemistry, vol. 66, no. 5, pp. 1995-2003, 1996.

[36] B. A. Yankner, L. R. Dawes, S. Fisher, L. Villa-Komaroff, M. L. Oster-Granite, and R. L. Neve, "Neurotixicity of a fragment of the amyloid precursor associated with Alzheimer's disease," Science, vol. 245, no. 4916, pp. 417-420, 1989.

[37] D. M. Hartley, D. M. Walsh, C. P. Ye et al., "Protofibrillar intermediates of amyloid $\beta$-protein induce acute electrophysiological changes and progressive neurotoxicity in cortical neurons," Journal of Neuroscience, vol. 19, no. 20, pp. 88768884, 1999.

[38] D. M. Walsh and D. J. Selkoe, "Deciphering the molecular basis of memory failure in Alzheimer's disease," Neuron, vol. 44, no. 1, pp. 181-193, 2004.

[39] G. M. Shankar, B. L. Bloodgood, M. Townsend, D. M. Walsh, D. J. Selkoe, and B. L. Sabatini, "Natural oligomers of the Alzheimer amyloid- $\beta$ protein induce reversible synapse loss by modulating an NMDA-type glutamate receptordependent signaling pathway," Journal of Neuroscience, vol. 27, no. 11, pp. 2866-2875, 2007.

[40] J. W. Allen, B. A. Eldadah, X. Huang, et al., "Multiple caspases are involved in beta-amyloid-induced neuronal apoptosis," Journal of Neuroscience Research, vol. 65, no. 1, pp. 45-53, 2001.

[41] F. Misiti, M. E. Clementi, G. Tringali et al., "Fragment 3135 of $\beta$-amyloid peptide induces neurodegeneration in rat cerebellar granule cells via bax gene expression and caspase- 3 activation. A crucial role for the redox state of methionine35 residue," Neurochemistry International, vol. 49, no. 5, pp. 525-532, 2006.

[42] A. Pannaccione, F. Boscia, A. Scorziello et al., "Up-regulation and increased activity of KV3.4 channels and their accessory subunit MinK-related peptide 2 induced by amyloid peptide are involved in apoptotic neuronal death," Molecular Pharmacology, vol. 72, no. 3, pp. 665-673, 2007.
[43] L. D. Plant, N. J. Webster, J. P. Boyle et al., "Amyloid $\beta$ peptide as a physiological modulator of neuronal 'A'-type $\mathrm{K}^{+}$ current," Neurobiology of Aging, vol. 27, no. 11, pp. 16731683, 2006.

[44] M. Pieri, G. Amadoro, I. Carunchio et al., "SP protects cerebellar granule cells against $\beta$-amyloid-induced apoptosis by down-regulation and reduced activity of $\mathrm{Kv} 4$ potassium channels," Neuropharmacology, vol. 58, no. 1, pp. 268-276, 2010.

[45] T. T. Rohn, R. A. Rissman, M. C. Davis, Y. E. Kim, C. W. Cotman, and E. Head, "Caspase-9 activation and caspase cleavage of tau in the Alzheimer's disease brain," Neurobiology of Disease, vol. 11, no. 2, pp. 341-354, 2002.

[46] L. Fasulo, G. Ugolini, M. Visintin et al., "The neuronal microtubule-associated protein tau is a substrate for caspase3 and an effector of apoptosis," Journal of Neurochemistry, vol. 75, no. 2, pp. 624-633, 2000.

[47] C.-W. Chung, Y.-H. Song, I.-K. Kim et al., "Proapoptotic effects of tau cleavage product generated by caspase-3," Neurobiology of Disease, vol. 8, no. 1, pp. 162-172, 2001.

[48] G. Amadoro, M. T. Ciotti, M. Costanzi, V. Cestari, P. Calissano, and N. Canu, "NMDA receptor mediates tauinduced neurotoxicity by calpain and ERK/MAPK activation," Proceedings of the National Academy of Sciences of the United States of America, vol. 103, no. 8, pp. 2892-2897, 2006.

[49] K. Leuner, S. Hauptmann, R. Abdel-Kader et al., "Mitochondrial dysfunction: the first domino in brain aging and Alzheimer's disease?" Antioxidants and Redox Signaling, vol. 9, no. 10, pp. 1659-1675, 2007.

[50] V. Rhein, G. Baysang, S. Rao et al., "Amyloid-beta leads to impaired cellular respiration, energy production and mitochondrial electron chain complex activities in human neuroblastoma cells," Cellular and Molecular Neurobiology, vol. 29, no. 6-7, pp. 1063-1071, 2009.

[51] M. Mancuso, F. Coppedè, L. Murri, and G. Siciliano, "Mitochondrial cascade hypothesis of Alzheimer's disease: myth or reality?" Antioxidants \& Redox Signaling, vol. 9, no. 10, pp. 1631-1646, 2007.

[52] W. D. Parker Jr., C. M. Filley, and J. K. Parks, "Cytochrome oxidase deficiency in Alzheimer's disease," Neurology, vol. 40, no. 8, pp. 1302-1303, 1990.

[53] K. Tieu, C. Perier, M. Vila et al., "L-3-hydroxyacyl-CoA dehydrogenase II protects in a model of Parkinson's disease," Annals of Neurology, vol. 56, no. 1, pp. 51-60, 2004.

[54] S. M. Cardoso, I. Santana, R. H. Swerdlow, and C. R. Oliveira, "Mitochondria dysfunction of Alzheimer's disease cybrids enhances A $\beta$ toxicity," Journal of Neurochemistry, vol. 89, no. 6, pp. 1417-1426, 2004.

[55] F. Bosetti, F. Brizzi, S. Barogi et al., "Cytochrome c oxidase and mitochondrial F1F0-ATPase (ATP synthase) activities in platelets and brain from patients with Alzheimer's disease," Neurobiology of Aging, vol. 23, no. 3, pp. 371-376, 2002.

[56] M. Mancuso, M. Filosto, F. Bosetti et al., "Decreased platelet cytochrome $c$ oxidase activity is accompanied by increased blood lactate concentration during exercise in patients with Alzheimer disease," Experimental Neurology, vol. 182, no. 2, pp. 421-426, 2003.

[57] A. Eckert, K .L. Schulz, V. Rhein, et al., "Convergence of amyloid-beta and tau pathologies on mitochondria in vivo," Molecular Neurobiology, vol. 41, no. 2-3, pp. 107-114, 2010.

[58] P. H. Reddy, "Mitochondrial dysfunction in aging and Alzheimer's disease: strategies to protect neurons," Antioxidants \& Redox Signaling, vol. 9, no. 10, pp. 1647-1658, 2007. 
[59] P. H. Reddy, "Amyloid beta, mitochondrial structural and functional dynamics in Alzheimer's disease," Experimental Neurology, vol. 218, no. 2, pp. 286-292, 2009.

[60] X. Chen and S. D. Yan, "Mitochondrial A $\beta$ : a potential cause of metabolic dysfunction in Alzheimer's disease," IUBMB Life, vol. 58, no. 12, pp. 686-694, 2006.

[61] F. M. LaFerla, K. N. Green, and S. Oddo, "Intracellular amyloid- $\beta$ in Alzheimer's disease," Nature Reviews Neuroscience, vol. 8, no. 7, pp. 499-509, 2007.

[62] C. A. Hansson Petersen, N. Alikhani, H. Behbahani et al., "The amyloid $\beta$-peptide is imported into mitochondria via the TOM import machinery and localized to mitochondrial cristae," Proceedings of the National Academy of Sciences of the United States of America, vol. 105, no. 35, pp. 13145-13150, 2008.

[63] L. Saavedra, A. Mohamed, V. Ma, S. Kar, and E. P. De Chaves, "Internalization of $\beta$-amyloid peptide by primary neurons in the absence of apolipoprotein E," Journal of Biological Chemistry, vol. 282, no. 49, pp. 35722-35732, 2007.

[64] K. E. Muirhead, E. Borger, L. Aitken, S. J. Conway, and F.J. Gunn-Moore, "The consequences of mitochondrial amyloid beta-peptide in Alzheimer's disease," Biochemical Journal, vol. 426, no. 3, pp. 255-270, 2010.

[65] C. Caspersen, N. Wang, J. Yao et al., "Mitochondrial A $\beta$ : a potential focal point for neuronal metabolic dysfunction in Alzheimer's disease," The FASEB Journal, vol. 19, no. 14, pp. 2040-2041, 2005.

[66] H. Du and S. S. Yan, "Mitochondrial permeability transition pore in Alzheimer's disease: cyclophilin D and amyloid beta," Biochimica et Biophysica Acta, vol. 1802, no. 1, pp. 198-204, 2010.

[67] P. Singh, S. Suman, S. Chandna, et al., "Possible role of amyloid-beta, adenine nucleotide translocase and cyclophilin-D interaction in mitochondrial dysfunction of Alzheimer's disease," Bioinformation, vol. 3, no. 10, pp. 440-445, 2009.

[68] R. A. Quintanilla, T. A. Matthews-Roberson, P. J. Dolan, and G. V. W. Johnsion, "Caspase-cleaved tau expression induces mitochondrial dysfunction in immortalized cortical neurons: implications for the pathogenesis of alzheimer disease," Journal of Biological Chemistry, vol. 284, no. 28, pp. 18754-18766, 2009.

[69] T. T. Rohn, E. Head, J. H. Su et al., "Correlation between caspase activation and neurofibrillary tangle formation in Alzheimer's disease," American Journal of Pathology, vol. 158, no. 1, pp. 189-198, 2001.

[70] M. C. Gastard, J. C. Troncoso, and V. E. Koliatsos, "Caspase activation in the limbic cortex of subjects with early Alzheimer's disease," Annals of Neurology, vol. 54, no. 3, pp. 393-398, 2003.

[71] J. L. Dinerman, T. M. Dawson, M. J. Schell, A. Snowman, and S. H. Snyder, "Endothelial nitric oxide synthase localized to hippocampal pyramidal cells: implications for synaptic plasticity," Proceedings of the National Academy of Sciences of the United States of America, vol. 91, no. 10, pp. 4214-4218, 1994.

[72] M. Zhuo, E. R. Kandel, and R. D. Hawkins, "Nitric oxide and cGMP can produce either synaptic depression or potentiation depending on the frequency of presynaptic stimulation in the hippocampus," Neuroreport, vol. 5, no. 9, pp. 10331036, 1994.

[73] G. R. J. Thatcher, B. M. Bennett, and J. N. Reynolds, "NO chimeras as therapeutic agents in Alzheimer's disease," Current Alzheimer Research, vol. 3, no. 3, pp. 237-245, 2006.
[74] D. Puzzo, O. Vitolo, F. Trinchese, J. P. Jacob, A. Palmeri, and O. Arancio, "Amyloid- $\beta$ peptide inhibits activation of the nitric oxide/cGMP/cAMP-responsive element-binding protein pathway during hippocampal synaptic plasticity," Journal of Neuroscience, vol. 25, no. 29, pp. 6887-6897, 2005.

[75] M. F. McCarty, "Toward prevention of alzheimers diseasepotential nutraceutical strategies for suppressing the production of amyloid beta peptides," Medical Hypotheses, vol. 67, no. 4, pp. 682-697, 2006.

[76] T. Pak, P. Cadet, K. J. Mantione, and G. B. Stefano, "Morphine via nitric oxide modulates $\beta$-amyloid metabolismml: a novel protective mechanism for Alzheimer's disease," Medical Science Monitor, vol. 11, no. 10, pp. BR357-BR366, 2005.

[77] D. Seyidova, A. Aliyev, N. Rzayev et al., "The role of nitric oxide in the pathogenesis of brain lesions during the development of Alzheimer's disease," In Vivo, vol. 18, no. 3, pp. 325-334, 2004.

[78] H. J. Lüth, M. Holzer, H.-J. Gertz, and TH. Arendt, "Aberrant expression of nNOS in pyramidal neurons in Alzheimer's disease is highly co-localized with p21(ras) and p16(INK4a)," Brain Research, vol. 852, no. 1, pp. 45-55, 2000.

[79] S. M. de la Monte, B.-X. Lu, Y.-K. Sohn et al., "Aberrant expression of nitric oxide synthase III in Alzheimer's disease: relevance to cerebral vasculopathy and neurodegeneration," Neurobiology of Aging, vol. 21, no. 2, pp. 309-319, 2000.

[80] M. H. Tran, K. Yamada, A. Olariu, M. Mizuno, X. H. Ren, and T. Nabeshima, "Amyloid $\beta$-peptide induces nitric oxide production in rat hippocampus: association with cholinergic dysfunction and amelioration by inducible nitric oxide synthase inhibitors," The FASEB Journal, vol. 15, no. 8, pp. 1407-1409, 2001.

[81] J. Haas, B. Storch-Hagenlocher, A. Biessmann, and B. Wildemann, "Inducible nitric oxide synthase and argininosuccinate synthetase: co-induction in brain tissue of patients with Alzheimer's dementia and following stimulation with $\beta$-amyloid 1-42 in vitro," Neuroscience Letters, vol. 322, no. 2, pp. 121-125, 2002.

[82] M. YU. Stepanichev, M. V. Onufriev, A. A. Yakovlev et al., "Amyloid- $\beta$ (25-35) increases activity of neuronal NOsynthase in rat brain," Neurochemistry International, vol. 52, no. 6, pp. 1114-1124, 2008.

[83] U. Keil, A. Bonert, C. A. Marques et al., "Amyloid $\beta$-induced changes in nitric oxide production and mitochondrial activity lead to apoptosis," Journal of Biological Chemistry, vol. 279, no. 48, pp. 50310-50320, 2004.

[84] K.-S. Ha, K.-M. Kim, Y.-G. Kwon et al., "Nitric oxide prevents 6-hydroxydopamine-induced apoptosis in PC12 cells through cGMP-dependent PI3 kinase/Akt activation," The FASEB Journal, vol. 17, no. 9, pp. 1036-1047, 2003.

[85] S. M. de la Monte and J. R. Wands, "Molecular indices of oxidative stress and mitochondrial dysfunction occur early and often progress with severity of Alzheimer's disease," Journal of Alzheimer's Disease, vol. 9, no. 2, pp. 167-181, 2006.

[86] H. Yuan, A. A. Gerencser, G. Liot et al., "Mitochondrial fission is an upstream and required event for bax foci formation in response to nitric oxide in cortical neurons," Cell Death and Differentiation, vol. 14, no. 3, pp. 462-471, 2007.

[87] M. J. Barsoum, H. Yuan, A. A. Gerencser et al., "Nitric oxideinduced mitochondrial fission is regulated by dynaminrelated GTPases in neurons," The EMBO Journal, vol. 25, no. 16, pp. 3900-3911, 2006. 
[88] D.-H. Cho, T. Nakamura, J. Fang et al., "S-nitrosylation of Drp1 mediates beta-amyloid-related mitochondrial fission and neuronal injury," Science, vol. 324, no. 5923, pp. 102-105, 2009.

[89] Z. Gu, T. Nakamura, and S. A. Lipton, "Redox reactions induced by nitrosative stress mediate protein misfolding and mitochondrial dysfunction in neurodegenerative diseases," Molecular Neurobiology, vol. 41, no. 2-3, pp. 55-72, 2010.

[90] B. Bossy, A. Petrilli, E. Klinglmayr, et al., "S-Nitrosylation of DRP1 does not affect enzymatic activity and is not specific to Alzheimer's disease," Journal of Alzheimer's Disease, vol. 20, no. 2, pp. 513-526, 2010.

[91] A. Jahani-Asl, E. C. C. Cheung, M. Neuspiel et al., "Mitofusin 2 protects cerebellar granule neurons against injury-induced cell death," Journal of Biological Chemistry, vol. 282, no. 33, pp. 23788-23798, 2007.

[92] B. Su, X. Wang, L. Zheng, G. Perry, M. A. Smith, and X. Zhu, "Abnormal mitochondrial dynamics and neurodegenerative diseases," Biochimica et Biophysica Acta, vol. 1802, no. 1, pp. 135-142, 2010.

[93] A. Nunomura, R. J. Castellani, X. Zhu, P. I. Moreira, G. Perry, and M. A. Smith, "Involvement of oxidative stress in Alzheimer disease," Journal of Neuropathology and Experimental Neurology, vol. 65, no. 7, pp. 631-641, 2006.

[94] B. Su, X. Wang, A. Nunomura et al., "Oxidative stress signaling in Alzheimer's disease," Current Alzheimer Research, vol. 5, no. 6, pp. 525-532, 2008.

[95] A. Jana and K. Pahan, "Fibrillar amyloid- $\beta$ peptides kill human primary neurons via NADPH oxidase-mediated activation of neutral sphingomyelinase:implications for Alzheimer's disease," Journal of Biological Chemistry, vol. 279, no. 49, pp. 51451-51459, 2004.

[96] P. B. Shelat, M. Chalimoniuk, J.-H. Wang et al., "Amyloid beta peptide and NMDA induce ROS from NADPH oxidase and AA release from cytosolic phospholipase A2 in cortical neurons," Journal of Neurochemistry, vol. 106, no. 1, pp. 4555, 2008.

[97] M. A. Smith, P. L. Richey Harris, L. M. Sayre, J. S. Beckman, and G. Perry, "Widespread peroxynitrite-mediated damage in Alzheimer's disease," Journal of Neuroscience, vol. 17, no. 8, pp. 2653-2657, 1997.

[98] M. R. Reynolds, J. F. Reyes, Y. Fu et al., “Tau nitration occurs at tyrosine 29 in the fibrillar lesions of Alzheimer's disease and other tauopathies," Journal of Neuroscience, vol. 26, no. 42, pp. 10636-10645, 2006.

[99] Y.-J. Zhang, Y.-F. Xu, Y.-H. Liu et al., "Peroxynitrite induces Alzheimer-like tau modifications and accumulation in rat brain and its underlying mechanisms," The FASEB Journal, vol. 20, no. 9, pp. 1431-1442, 2006.

[100] T. Horiguchi, K. Uryu, B. I. Giasson et al., "Nitration of tau protein is linked to neurodegeneration in tauopathies," American Journal of Pathology, vol. 163, no. 3, pp. 1021-1031, 2003.

[101] C. J. Pike, J. C. Carroll, E. R. Rosario, and A. M. Barron, "Protective actions of sex steroid hormones in Alzheimer's disease," Frontiers in Neuroendocrinology, vol. 30, no. 2, pp. 239-258, 2009.

[102] J. E. Rossouw, G. L. Anderson, R. L. Prentice et al., "Risks and benefits of estrogen plus progestin in healthy postmenopausal women: principal results from the women's health initiative randomized controlled trial," Journal of the American Medical Association, vol. 288, no. 3, pp. 321-333, 2002.
[103] G. Perry, A. D. Cash, and M. A. Smith, "Alzheimer disease and oxidative stress," Journal of Biomedicine and Biotechnology, vol. 2002, no. 3, pp. 120-123, 2002.

[104] O. Y. Bang, H. S. Hong, D. H. Kim et al., "Neuroprotective effect of genistein against beta amyloid-induced neurotoxicity," Neurobiology of Disease, vol. 16, no. 1, pp. 21-28, 2004.

[105] H. Zeng, Q. Chen, and B. Zhao, "Genistein ameliorates $\beta$-amyloid peptide (25-35)-induced hippocampal neuronal apoptosis," Free Radical Biology and Medicine, vol. 36, no. 2, pp. 180-188, 2004.

[106] N. J. Linford and D. M. Dorsa, " $17 \beta$-Estradiol and the phytoestrogen genistein attenuate neuronal apoptosis induced by the endoplasmic reticulum calcium-ATPase inhibitor thapsigargin," Steroids, vol. 67, no. 13-14, pp. 1029-1040, 2002.

[107] J. M. Andersen, O. Myhre, and F. Fonnum, "Discussion of the role of the extracellular signal-regulated kinasephospholipase A2 pathway in production of reactive oxygen species in Alzheimer's disease," Neurochemical Research, vol. 28, no. 2, pp. 319-326, 2003.

[108] H.-L. Yu, L. Li, X.-H. Zhang et al., "Neuroprotective effects of genistein and folic acid on apoptosis of rat cultured cortical neurons induced by beta-amyloid 31-35," British Journal of Nutrition, vol. 102, no. 5, pp. 655-662, 2009.

[109] Y.-J. Park, Y.-M. Jang, and Y. H. Kwon, "Isoflavones prevent endoplasmic reticulum stress-mediated neuronal degeneration by inhibiting tau hyperphosphorylation in SH-SY5Y Cells," Journal of Medicinal Food, vol. 12, no. 3, pp. 528-535, 2009.

[110] A. Atlante, A. Bobba, G. Paventi, R. Pizzuto, and S. Passarella, "Genistein and daidzein prevent low potassium-dependent apoptosis of cerebellar granule cells," Biochemical Pharmacology, vol. 79, no. 5, pp. 758-767, 2010.

[111] S. L. Vallés, C. Borrás, J. Gambini et al., "Oestradiol or genistein rescues neurons from amyloid beta-induced cell death by inhibiting activation of p38," Aging Cell, vol. 7, no. 1, pp. 112-118, 2008.

[112] Q. Cai and H. Wei, "Effect of dietary genistein on antioxidant enzyme activities in SENCAR mice," Nutrition and Cancer, vol. 25, no. 1, pp. 1-7, 1996.

[113] P. Foti, D. Erba, P. Riso, A. Spadafranca, F. Criscuoli, and G. Testolin, "Comparison between daidzein and genistein antioxidant activity in primary and cancer lymphocytes," Archives of Biochemistry and Biophysics, vol. 433, no. 2, pp. 421-427, 2005. 


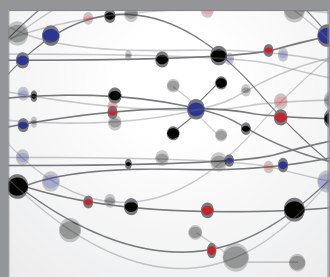

The Scientific World Journal
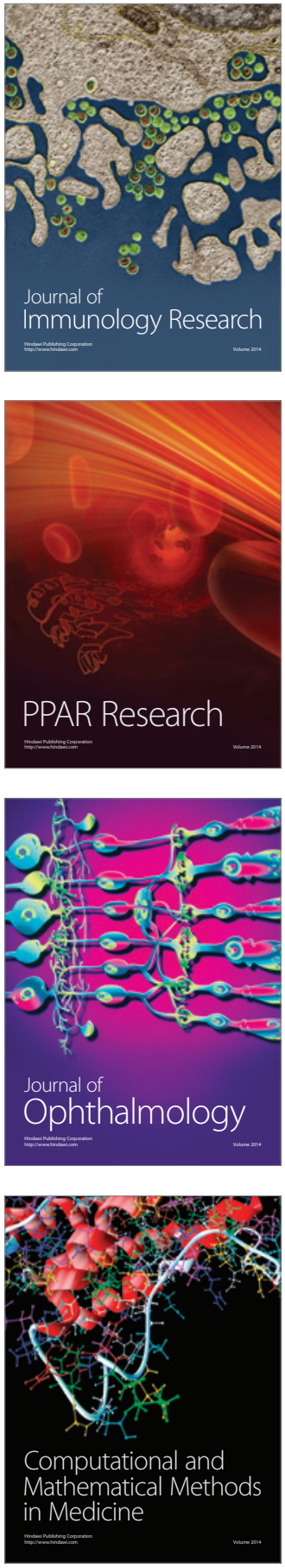

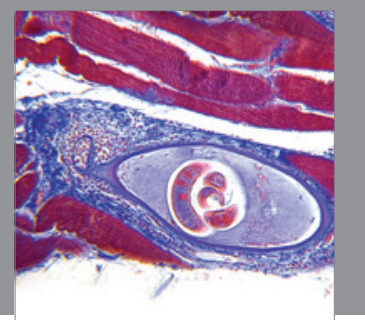

Gastroenterology

Research and Practice
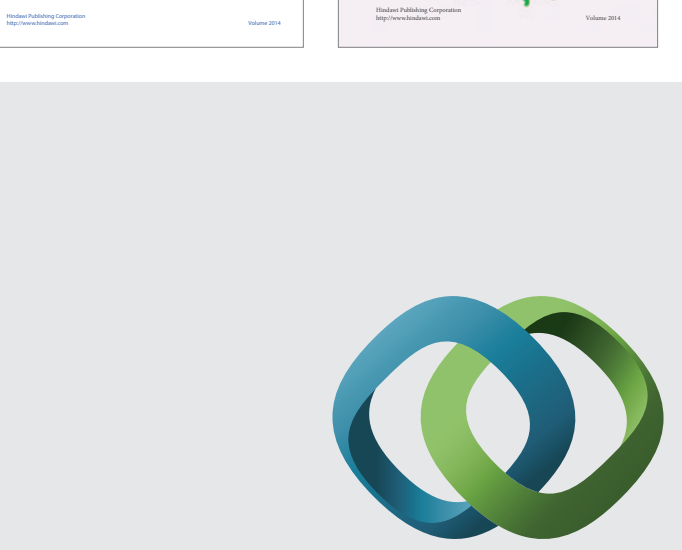

\section{Hindawi}

Submit your manuscripts at

http://www.hindawi.com
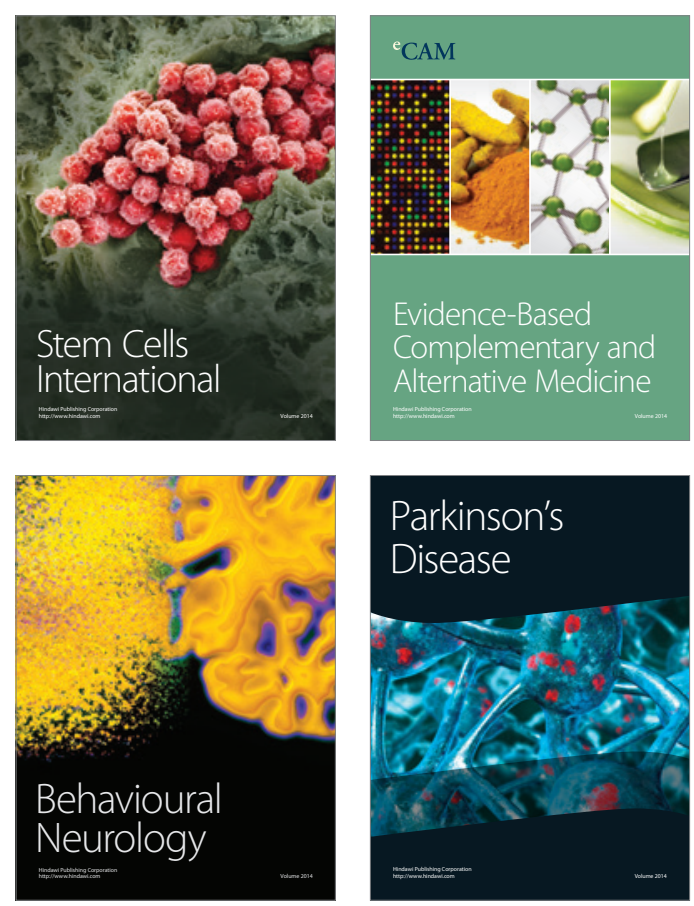

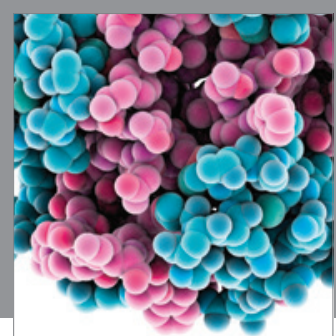

Journal of
Diabetes Research

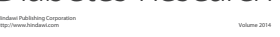

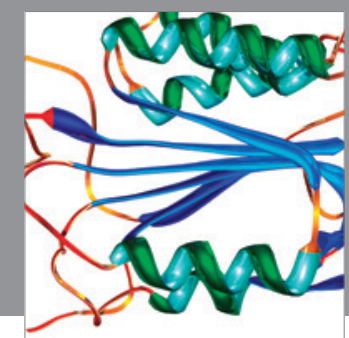

Disease Markers
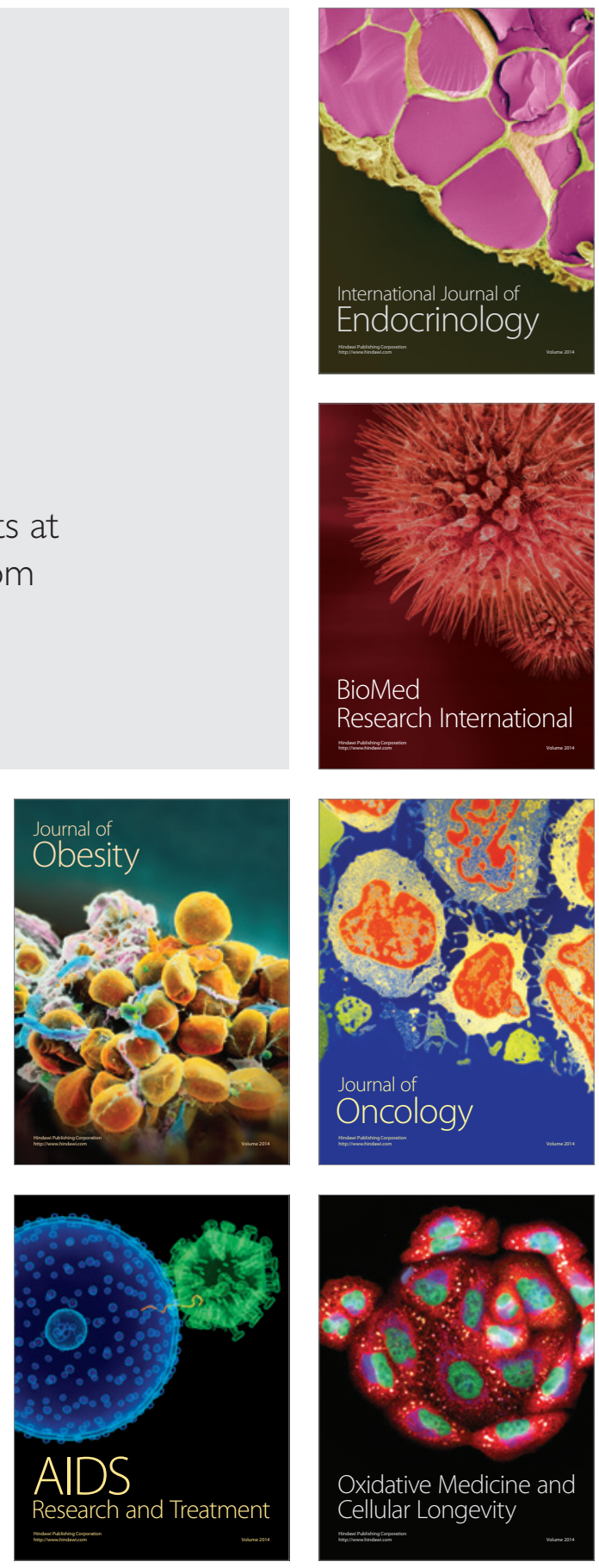